Irish Math. Soc. Bulletin

Number 82, Winter 2018, 69-78

ISSN 0791-5578

\title{
The Story of Ireland's Participation in the 29th International Mathematical Olympiad in Australia
}

\author{
FINBARR HOLLAND, THOMAS LAFFEY
}

\begin{abstract}
We present a short sequential account of the major events that led to Ireland's participation in its first International Mathematical Olympiad when this was held in Canberra in 1988 as part of the celebrations to mark the bicentenary of the settlement of Australia by Europeans.
\end{abstract}

\section{INTRODUCTION}

In 1788, a fleet of British convict ships sailed into Sydney harbour to land the first Europeans to settle in Australia. To mark the bicentenary of this momentous event, the Australian Government decided in 1980 to host a series of cultural events at major Australian cities. The International Mathematical Olympiad (IMO) was one such event that was approved to be held in the capital Canberra, and Mr Peter O' Halloran, of Canberra College of Education, was appointed to organise it. Not only did O' Halloran set about attracting competitors from countries in the vicinity of Australia that had never before taken part in the IMO - which, up to then, had largely attracted contestants from European countries that had a long tradition of participating in it - but, being proud of his Irish ancestry, and conscious that $20 \%$ of the Australian population was deemed to be of Irish descent, he was anxious that Ireland be represented at the 29th IMO in Canberra in 1988.

With this in mind, O' Halloran wrote to the Royal Irish Academy (RIA) in 1985, requesting information about mathematical contests being run in Ireland. His request was duly passed to the Irish National Mathematics Committee, a sub-committee of the RIA, of which both of us were then members. As luck would have it, we

2010 Mathematics Subject Classification. 97U40.

Key words and phrases. Mathematical Olympiad, Mathematical Contests, Ireland.

Received on 5-11-2018. 
were also co-organisers of the Irish National Mathematics Contest, an annual competition for secondary school pupils in the whole of Ireland, which we had commenced in 1979. This initial contact with O'Halloran, which we followed up, was the first step in Ireland's future involvement in the IMO.

What follows is an account of the sequencing of the major events that led to Ireland's participation in the 29th IMO in Australia. It is a short historical account of the back story leading to Ireland's involvement in its first IMO, the 30th anniversary of which, inter alia, was commemorated in Cork at the Award Ceremony organised by the Irish Mathematical Trust in May, 2018; it incorporates elements of separate speeches each of us gave on that occasion.

\section{The Formation of the Irish Mathematical Society}

The story begins with the formation of the Irish Mathematical Society (IMS). This grew out of biannual meetings of mathematicians of different hues which were held during university Christmas and Easter vacations at the Dublin Institute for Advanced Studies (DIAS), established by Eamon de Valera in 1940. In the early years of its existence, the DIAS was located in 64/65 Merrion Square, Dublin, before moving to its present site at 10, Burlington Road, Dublin. These Mathematical Symposia were organised initially by John Lighton Synge, and later by John Lewis, and attracted theoretical physicists, mathematical physicists and mathematicians from university colleges north and south of the border, as well as from across the water. Those who contributed lectures received honoraria, and all attendees were able to recoup their travel expenses. These incentives to participate and contribute were greatly appreciated by those who attended, and appealed to university staff and graduate students alike, especially Irish graduates studying abroad for higher degrees who came home at Christmas and Easter when the Symposia were held. These meetings were both cultural and social events: as well as exchanging ideas in the lecture room, the latest mathematical theories and academic gossip were exchanged over a pint or two afterwards in a nearby hostelry! These occasions were the breeding ground for the inception of the IMS, which was formed in 1975. It was well established by 1977, and the annual accounts for that year show that 80 people each paid a membership fee of 2 Irish pounds. 
Early in the life of the IMS a decision was taken to run a National Mathematical Contest for secondary students, to promote their interest in mathematics and increase their awareness of its importance by posing challenging mathematical problems in a competitive environment. Part of the motivation for initiating such a contest was also to identify and enter a team in the IMO, a passionate desire of the authors, who were given the task of developing this idea. They were faced with some obvious questions: What would be a suitable model for such a contest? Who would administer it? Where would it be held? Who would set the problems? Examine the solutions? Cover the cost? A myriad of similar questions would need to be examined before the idea could be brought to fruition.

\section{The Origins of the Irish National Mathematics CONTEST}

Of course, by that time, there were many mathematical contests of various kinds being run in different countries, all inspired by those run for many years in Hungary, their chief aim being to foster interest in Mathematics at second level. From about 1977 the first author $(\mathrm{FH})$ investigated many of the known international contests and his searches led him, for example, to examine, in particular, the format and structure of the Scottish Mathematical Challenge, which was conducted by correspondence, and that being run in England by the Mathematical Association. The structure of the latter was appealing: it was a 90-minute multiple choice test, marked by teachers. And even better still, the problems and their solutions were imported from the USA! In September, 1978, FH contacted Mr Gray, Secretary of the UK Mathematical Association for more details, and raised the possibility of extending the same test to Irish pupils. It turned out that they were using the American High School Mathematics Examination (AHSME) paper which was administered by Dr Walter Mientka, University of Nebraska. On foot of this information, FH wrote directly to Mientka, and obtained his permission to model the INMC on this paper. Sometime in the Autumn of 1978, Mientka forwarded a master copy of the paper, and an accompanying solution booklet for AHSME 1979 to FH. Upon receipt of the master copy of the AHSME and the solutions booklet, the rest was relatively straightforward. The second author (TL) assented to it, the officers of the fledging IMS adopted our proposal to 
model the INMC on the AHSME, and wholeheartedly backed the idea. Both of us were appointed to implement it, and we agreed to share the administrative load between us, TL taking responsibility for administering the contest in Leinster, and $\mathrm{FH}$ in the rest of Ireland. By this stage, too, the Irish Mathematics Teachers Association (IMTA) was also on board, and we wish to acknowledge, in particular, the support we received from Fred Holland, of Holland \& Madden fame - Fred was a highly influential member of the IMTA, and he played an important role in persuading its members to endorse the project. The cooperation of school teachers was essential to administer the examination during a suitable slot in the school timetable, and report the results to one of us afterwards. We're very conscious of all the necessary assistance we received from many different teachers over the years, without which the INMC could not have been run, and record our gratitude to all of them, who are too numerous to name.

In late 1978, letters were dispatched by both of us to secondary schools north and south of the border inviting them to enter pupils in the 1979 contest, which was to be given on March 6,1979, the same day it was to be administered in the USA, and to pay a small fee per entry to cover postage and printing costs. Based on the response from schools, and armed with the number of entries, FH then made small editorial adjustments to the master copy, and placed an order with the UCC printer for an appropriate number of copies of the test paper and duplicates of the solution booklet.

A batch of these were fast-tracked by train to TL some days before the due examination date, and he mailed them out to schools in the Leinster area; FH likewise looked after schools in Munster, Connacht and Ulster. Results were compiled, circulated to participating schools, published in the IMS Newsletter (as the IMS Bulletin was then called), and prizes awarded to the top scorers at a ceremony organised for them and their teachers by TL in UCD early in December 1979.

So, the first INMC took place on March 6,1979, and continued for many years thereafter with the same format, with the assistance and support of Fergus Gaines in UCD, and Donal Hurley in UCC, who took over the production and distribution of the examination papers whenever $\mathrm{FH}$ was absent for any reason. For instance, the 20th INMC occurred on Tuesday, 9th February, 1999, and coincided 
with the holding of the 50th AHSME. On the occasion of the prizegiving ceremony for the top scorers held that year on December 10,1999, a perpetual trophy donated by the IMS was presented to the winner of the INMC. Incidentally, from 1983 onwards, a second competition, called the Irish Invitational Mathematics Contest, was offered to the top scorers of the INMC, the materials for which we also received from Mientka.

\section{The Role of Peter O' Halloran}

Sometime in 1985, the RIA received a copy of the 2 nd issue of the Newsletter produced by the World Federation of National Mathematics Competitions, and the cover letter with it sought information about mathematics contests in Ireland. This letter came from Peter O' Halloran, who had been appointed Chairman of the Australian Commission set up to organise the IMO in Australia in 1988. Being proud of his Irish heritage Peter was anxious that Ireland participate in the celebrations, and entering an IMO team that year would be an appropriate way to do this. FH responded to O'Halloran's letter, expressing our interest in the idea, but pointing out reasons why we didn't think it was a feasible prospect at that time. We felt that suitable team members were very likely to be engaged in sitting Matriculation examinations for the NUI and/or TCD during the first fortnight of July, followed by University Entrance Scholarship examinations. They couldn't possibly be in two places at the same time, and, more importantly, couldn't be expected to run the risk of forfeiting their chances of getting a university place and possibly a scholarship as well. In addition, we felt that it would be nigh to impossible to get a sponsor who would be prepared to cover the travel costs. But Peter, waiving aside our perceived difficulties and objections - which he felt could be overcome - persisted, expressing a strong wish for an Irish team to be entered in the competition, given the history of the two countries. The year 1988 marked the Bicentennial of the settlement of Australia by Europeans, and was going to be celebrated hugely in Australia a fifth of whose population was of Irish descent. It was important therefore that Ireland mark the occasion, and sending a team to the 29 th IMO would be a fitting way to do so.

We continued to exchange correspondence with O' Halloran about the prospect of sending an Irish MO team. (FH made the mistake 
of giving him his telephone number, which meant that he started getting early morning phone calls all the way from Australia!) Peter informed us that he was coming to Ireland in the Summer of 1986, ostensibly to trace his ancestors, and we agreed to meet him and explore further the possibility of Ireland sending a team. In the meantime, he was busy working behind the diplomatic scenes, and had made contact with the Irish Ambassador to Australia urging him to progress his ideas. In particular, he arranged to visit the Australian Ambassador to Ireland during his own visit to Ireland.

As promised, Peter and his wife Marjorie duly arrived in Ireland in the middle of July, 1986, and we met them. We accompanied Peter to discuss the matter with Paddy Cooney, TD, then Minister for Education, who had by then received a formal invitation from the Minister assisting the Prime Minister of Australia for Bicentennial Affairs to participate in the IMO, and subsequently Peter Barry, TD, then Minister for Foreign Affairs. These meetings had been set up by the Australian Ambassador to Ireland, whom Peter had met in advance of meeting us. At our meetings with Barry and Cooney, we set out our tentative plans and a strategy for identifying and preparing an Irish team for the 29th IMO, and provided rough costs of the venture. Our meeting with Paddy Cooney was very relaxed, partly aided by the fact that Paddy and the Australian Ambassador to Ireland both had great respect for the education provided by the Marist Brothers in their respective countries - a topic of conversation that was sparked by O' Halloran! By contrast, we were whisked in and out of Minister Barry's presence and our memory of the meeting is a blur. In the ante room we furnished a rough guide to one of his officials of the amount of money we thought we might need, but subsequently mentioned a larger estimate to the Minister, and were somewhat taken aback when the official expressed his annoyance with us about the disparity in amounts when we were leaving! But the essential thing that emerged from the meetings was that both Ministers gave their approval for the venture and indicated that a small committee would be set up to progress the matter; and, more significantly, indicated that finance would be forthcoming. Shortly afterwards, a committee comprising of both of us, Bill Nolan from the Department of Foreign Affairs and an t-Uasal Conchubhair Ó Chaoimh from the Department of Education, was set up, under the latter's chairmanship, to deal with the logistics. (The presence of a 
representative from Foreign Affairs proved invaluable in dealing with late applications for passports for team members, and visas to the country hosting the IMO. Much later, for instance, when the IMO was held in Argentina, the Irish Ambassador in Buenos Aires arrived at the airport to greet the Irish team led by the Deputy Leader, Gordon Lessells, only to discover that Raja Mukherji, a team member, wasn't being allowed to enter the country because - though born in Ireland, and therefore entitled to an Irish one - he was travelling on an Indian passport! The Ambassador quickly resolved the matter by issuing an Irish passport to Raja which qualified him for a visa to enter Argentina as an Irish MO team member.)

\section{Attendance at the 28th IMO in Cuba}

Following a series of meetings of the committee of four, strategies were agreed for identifying talented students, for coaching them and raising funds. It was also decided to send an observer to the 28th IMO which was to be held in Cuba in 1987. FH was elected to go there and he wrote to the organiser, Luis Davidson, for particulars about the 1987 IMO. But by the end of May, 1987, FH still hadn't heard anything from Davidson. However, his trip had been sanctioned by that time, and FH made plans to go to Havana on the advice of Peter O' Halloran, with whom FH had shared his concerns about the lack of information from Cuba.

His attendance there was an invaluable learning experience. He saw at first hand how everything worked at an IMO, and as well as renewing acquaintanceship with O' Halloran made contact with Leaders, and Observers from other countries, such as Emanuel Strzelecki from Australia, Ronald Dunkley from Canada and Derek Holton, from New Zealand-who, like FH, was also attending his first IMO - all of whom shared their own experiences of identifying and training their teams. He made lasting friendships with people from other countries as well, and came home armed with advice, problem sets and training materials - and cigars very few of which he smoked! - but minus several items of clothing which went missing at the airport whence he departed!

\section{Preparations for 29th imO in Australia}

These began in earnest on FH's return from the 28th IMO in Cuba! A selection of the top scorers of the INMC for 1987 who were 
still in school, and other talented students identified to us by their teachers, were invited to attend special coaching sessions in UCD and UCC on specific topics not covered by the Leaving Certificate programme. These were given by us with the assistance of some staff members of the UCC and UCD Mathematics Departments, such as Fergus Gaines and Donal Hurley, on a voluntary basis, and by local teachers who helped from time to time in the venture. The first Irish Mathematical Olympiad papers were set, and the top six scorers formed the team to represent Ireland at the 29th IMO. The Minister for Education covered the travel costs for six team members and two leaders, and the rest is history! Every year since then, the Minister has provided just enough funding to cover travel costs of 8 people, and sometimes an observer, to represent Ireland at that year's IMO, the country hosting the event bearing local accommodation and travel costs associated with the contest.

In July of 1988, a group of ten Irish people from different parts of Ireland gathered in Heathrow Airport to board a Qantas Airlines plane which was to take us to Sydney to compete in the 29th IMO which was being hosted in Canberra, the first IMO to be held in the southern hemisphere. The party included two female and four male students, TL as Deputy Leader, FH as Team Leader, and his wife Mae and daughter Allison as accompanying persons.

We were all giddy with excitement when we assembled at the airport, and very nearly missed our flight because we ended up in the wrong terminal! But we recovered our bearings quickly enough and boarded our flight on time, to begin our adventure.

On arrival in Sydney we spent approximately one day there before being transported by bus to Canberra, where our party was split up: along with other deputy leaders and team members, Allison, TL and the six team members were accommodated in a Hall of Residence for students in the College of Education, where the contest was to be held, while, some distance away from the students, FH and Mae were allocated to a separate apartment in a residential complex attached to the Australian Academy of Science, which is where the Team Leaders were billeted. This was adjacent to the Academy's Shine Dome, where for about two days the Jury deliberated over the rules and regulations of the IMO, and composed and translated the examination papers, which consisted of six problems selected from a short list prepared by the local coordinators from 
those submitted by different countries. One such problem had been submitted by Ireland, and following the examination it fell to TL and $\mathrm{FH}$ to decide what marks to award to each Australian team member who attempted it. This problem traces back to an integral identity established by George Boole on the eve of his taking up his appointment as the first Professor of Mathematics at the Queen's College, Cork, in 1849, and the key idea for this also crops up in Lynn Loomis's real variable treatment of the Hilbert transform in 1946, about which FH learnt following Adriano Garsia's seminar about this transform when he was in Caltech during 1964-65. This concerned the size of the set of intervals where the finite Hilbert transform

$$
\sum_{j=1}^{n} \frac{c_{j}}{x-a_{j}}, a_{j} \in(-\infty, \infty), c_{j}>0, j=1,2, \ldots, n,
$$

is bigger than a given positive real number $y$. The 4 th problem chosen for the 29th IMO was a special case of this result. Of the attempts made on it by the Australian team members, one stood out - that by Terry Tao, then aged 13, who was competing at an IMO for the third time, having previously won a bronze medal in 1986, and a silver one in 1987. Tao's solution of Problem 4 was a model of clarity, rigour and elegance, and left an indelible mark on both of us; even then he was clearly destined for a bright future, and his subsequent career hasn't disappointed. Since winning an IMO gold medal in Canberra - the youngest ever to win one-Tao has made outstanding contributions to several areas of mathematics, has published more than 300 papers with as many as 60 different authors, maintains a very active blog, which has spawned several of his 15 or so books, and has won many honours, including a Fields medal in 2006. Our examination of Tao's solution of Problem 4 at the 29th IMO in Canberra was the mathematical highlight of our involvement in this event.

In conclusion, that journey to Canberra made thirty years ago was the first of many subsequent trips made abroad by different sets of Irish students, different leaders and deputy leaders every year since 1988 to a country hosting the IMO, to compete in an event which has taken place every year, excluding 1980, since the first was held in Romania in 1959, when only 7 countries competed. Nowadays, that number has swelled to more than 100 from 5 continents, and 
nearly 600 students participated this year in the 59th IMO held in Cluj-Napoca, Romania.

Finbarr Holland graduated from UCC with a BSc in Mathematics and Mathematical Physics in 1961. He was awarded a Travelling Studentship, and the MSc degree, by the NUI in 1962. The Studentship enabled him to study for his PhD in Harmonic Analysis under the supervision of Lionel B. Cooper at University College, Cardiff; and the National University of Wales conferred this degree on him in 1964. He joined the staff of the Mathematics Department at UCC in 1965, where he currently holds the rank of Professor Emeritus.

Thomas Laffey graduated from UCG with a BSc in Mathematical Science in 1964 and an MSc in Mathematical Science in 1965. After one year teaching in the Department of Mathematics at UCG, he went on a tutorial studentship to Sussex University and, under the supervision of Walter Ledermann, graduated with a D.Phil. in Finite Group Theory in 1968. He joined the staff of the Department of Mathematics at UCD later that year, and he currently holds the rank of Professor Emeritus there.

(Finbarr Holland) School of Mathematical Sciences, University ColLEGE CORK.

(Thomas Laffey) School of Mathematical Sciences, University ColLEGE DUBLIN.

E-mail address: f.holland@ucc.ie, thomas.laffey@ucd.ie 